\title{
VfZ-Online
}

\section{Kommentar im VfZ-Forum und Aufzeichnung des „Podiums Zeitge- schichte“ 2020}

Ein neuer Kommentar im VfZ-Forum

Der ungarische Zeithistoriker Krisztián Ungváry hat für das Forum von VfZ-Online den Gastbeitrag „75 Jahre Kriegsende: Keine Politik ohne Geschichte“ kommentiert, den Bundesaußenminister Heiko Maas zusammen mit Andreas Wirsching, Direktor des Instituts für Zeitgeschichte München-Berlin und Herausgeber der Vierteljahrshefte für Zeitgeschichte, im Mai 2020 für das Nachrichtenmagazin Der Spiegel verfasst hat. Der Diskussionsbeitrag ist nachzulesen unter:

https://www.ifz-muenchen.de/vierteljahrshefte/forum

Aufzeichnung des „Podiums Zeitgeschichte“ 2020

Mit dem knappen Sieg Joe Bidens bei der Wahl in den USA am 3. November 2020 beginnt Donald Trumps Präsidentschaft, Geschichte zu werden. Die Verwerfungen dieser Präsidentschaft haben die VfZ veranlasst, ihr viertes „Podium Zeitgeschichte" den deutsch-amerikanischen Beziehungen zu widmen. Dabei ging es vor allem darum, Faktoren der Stabilität und des Wandels im gegenseitigen Verhältnis herauszuarbeiten, Kontinuitäten und Zäsuren zu untersuchen, dem spezifischen Gewicht organisatorischer Strukturen oder biografischer Konstellationen nachzuspüren sowie nach den Grenzen des transatlantischen Verständnisses und damit auch nach den Grenzen der Amerikanisierung in Deutschland zu fragen. In fünf Längsschnitten boten Philipp Gassert, Andreas Etges, Stormy-Annika Mildner, Michael Hochgeschwender sowie Reinhild Kreis und Jan Logemann im OktoberHeft 2020 einen problemorientierten Überblick über die Geschichte der deutschamerikanischen Beziehungen seit 1945 und setzten so auch einen Orientierungsrahmen für die aktuelle Debatte. Am Montag, 16. November 2020, diskutierten Philipp Gassert, Andreas Etges, Stormy-Annika Mildner und Jan Logemann - moderiert von Andreas Wirsching und Thomas Schlemmer - im Licht des jüngsten Wahlergebnisses über das transatlantische Verhältnis und seine Perspektiven. Die Veranstaltung fand digital in Form eines Zoom-Webinars statt; die Aufzeichnung ist auf VfZ-Online verfügbar:

https://www.ifz-muenchen.de/vierteljahrshefte/podium-zeitgeschichte/ 